\title{
Estudo pré-analítico e de validação para determinação de malondialdeído em plasma humano por cromatografia líquida de alta eficiência, após derivatização com 2,4-dinitrofenilhidrazina
}

\author{
Marina Venzon Antunes, Camilla Lazzaretti, Giovana Duzzo Gamaro, Rafael Linden* \\ Laboratório de Análises Toxicológicas, Instituto de Ciências da Saúde, Centro Universitário Feevale
}

*Correspondência:

R. Linden

Laboratório de Análises Toxicológicas Instituto de Ciências da Saúde

Centro Universitário Feevale

Rodovia RS 239, n. 2755

93352-000 - Novo Hamburgo - RS,

Brasil

E-mail: rafael.linden@feevale.br
O malondialdeído (MDA) é um importante biomarcador utilizado na avaliação do estresse oxidativo. O objetivo deste estudo foi desenvolver uma metodologia para a quantificação plasmática de MDA, através de cromatografia líquida de alta eficiência com detecção por arranjo de diodos (CLAE-DAD), após processo de derivatização com 2,4-dinitrofenilhidrazina (DNPH), avaliando as principais variáveis pré-analíticas. A curva de calibração em plasma (0 a $40 \mu \mathrm{M}$ ) apresentou elevada linearidade $\left(r^{2}=0,998\right)$. Os principais parâmetros de validação foram: recuperação absoluta: 78\%; limite de detecção: 0,11 $\mu \mathrm{M}$ e limite de quantificação: 0,38 $\mu \mathrm{M}$. Os valores de MDA determinados em individuos adultos saudáveis $(n=38)$ foram 3,31 $\pm 0,38 \mu M$ (média $\pm D P)$. Estudos de estabilidade do padrão de $M D A$, reagente derivatizante e MDA plasmáticos, indicaram que a solução padrão pode ser armazenada $a-20$ e $4{ }^{\circ} \mathrm{C}$.
Unitermos

- Estresse oxidativo

- Malondialdeído

- Cromatografia líquida de alta eficiência

- 2,4-dinitrofenilhidrazina

\section{INTRODUÇÃO}

No processo de respiração celular, a redução tetravalente do oxigênio pode gerar espécies reativas ao oxigênio (EROs). Em situações de equilíbrio as EROs são neutralizadas pelos antioxidantes, porém em algumas situações pode ocorrer um desequilíbrio entre formas oxidantes e antioxidantes, gerando estresse oxidativo (Ferreira, Matsubara, 1997).

Todos os componentes celulares são suscetíveis à ação das EROs frente ao estresse oxidativo, porém a membrana é um dos mais atingidos em decorrência da peroxidação lipídica, que acarreta alterações na sua estrutura e permeabilidade (Ferreira, Matsubara, 1997).
Os produtos da peroxidação lipídica, como o malondialdeído (MDA, $\mathrm{C}_{3} \mathrm{H}_{4} \mathrm{O}_{2}$ ), podem ser utilizados como indicadores da ação dos radicais livres no organismo (Ferreira, Matsubara, 1997; Del Rio, Stewart, Pellegrini, 2005; Özgüner et al., 1999). O MDA possui ação citotóxica e genotóxica, encontrando-se em níveis elevados em algumas patologias associadas ao estresse oxidativo (Andrade Jr et al., 2005; Steghens et al., 2001; Bagis et al., 2005).

A quantificação de MDA nos sistemas biológicos é um parâmetro importante para avaliação do estresse oxidativo celular (Pilz, Meineke, Gleiter, 2000; Sim et al., 2003). O método introduzido por Yagi (1976) tem sido amplamente utilizado. O princípio deste método consiste na reação do MDA com o ácido tiobarbitúrico (TBA), sendo 
o produto detectado através de leitura espectrofotométrica na região do visível. Embora este método ainda seja amplamente utilizado, ele não é específico para detecção dos produtos de peroxidação lipídica (Steghens et al., 2001), uma vez que quantifica a soma das diferentes substâncias reativas ao ácido tiobarbitúrico, denominadas TBARS. Desta forma, os valores de TBARS incluem interferentes provenientes da reação do TBA com outras substâncias presentes na amostra, como por exemplo, carboidratos e proteínas (Steghens et al., 2001; Pilz, Meineke, Gleiter, 2000; Sim et al., 2003; Korchazhkina, Exley, Spencer, 2003; Yeo et al., 1994). Além disso, este método propicia geração in vitro de aldeídos devido às condições experimentais de incubação em temperatura elevada $\left(96^{\circ} \mathrm{C}\right)$, por 1 hora, em meio ácido (Steghens et al., 2001).

Com o propósito de obter determinações mais específicas e sensíveis para a quantificação do MDA em amostras biológicas, diversas metodologias com emprego de cromatografia líquida de alta eficiência (CLAE) têm sido propostas (Steghens et al., 2001; Pilz, Meineke, Gleiter, 2000; Sim et al., 2003; Karatas, Karatepe, Baysar, 2002; Londero, Greco, 1996; Mao et al., 2006; Grotto et al., 2007). Os métodos propostos por Steghens et al. (2001), Pilz, Meineke, Gleiter (2000) e Mao et al. (2006) quantificam, além do MDA total, também a sua forma livre. Entretanto, pouco se sabe sobre a significância fisiopatológica da quantificação das formas livre e ligada (Del Rio, Stewart, Pellegrini, 2005). Dados da literatura demonstram valores de concentrações plasmáticas inferiores a $0,2 \mu \mathrm{M}$ para a forma livre.

Uma estratégia comum para melhorar a sensibilidade dos métodos de CLAE com detectores UV, em face da pequena absortividade molar do MDA, é o emprego de agentes derivatizantes. Nos trabalhos de Grotto et al. (2007) e Londero, Greco (1996), foram utilizadas condições de derivatização similares àquelas empregadas no método espectrofométrico de determinação de MDA, com o uso de TBA como derivatizante. Nestes estudos, a reação entre MDA e TBA ocorreu em temperaturas elevadas, o que pode acarretar formação in vitro de TBARS.

Alternativamente, outros derivatizantes também têm sido empregados. Um derivatizante de uso freqüente na determinação de aldeídos por CLAE-UV é a 2,4dinitrofenilhidrazina (DNPH) (Pilz, Meineke, Gleiter, 2000; Sim et al., 2003; Mateos et al., 2005). O DNPH apresenta como característica vantajosa o emprego de condições experimentais brandas, baixo custo e rápida reação com aldeídos (Sim et al., 2003). Em ensaios que utilizam como derivatizante 9-fluorenilmetoxi-carbonilhidrazina, ocorre a formação de produto detectável por fluorescência. Alternativamente, Karatas, Karatepe e Baysar (2002) re- lataram a determinação de MDA em plasma humano por CLAE-UV sem o uso de derivatizantes.

Os valores de referência para os níveis de MDA total relatados na literatura apresentam grande variabilidade, estando relacionados com as condições experimentais utilizadas nos diferentes ensaios. Desta forma, os valores de MDA plasmático determinados para indivíduos saudáveis por Steghens et al. (2001) são 0,138 $\pm 0,028 \mu \mathrm{M}$, enquanto que para Pilz, Meineke e Gleiter (2000) são 2,16 $\pm 0,29 \mu \mathrm{M}$, em contraste com os valores obtidos por Sim et al. (2003) de 13,8 $\pm 1,32 \mu \mathrm{M}$, Londero e Greco (1996) de $0,85 \pm 0,25 \mu \mathrm{M}$ e Mao et al. (2006), de 0,426 $\pm 0,029$ $\mu \mathrm{M}$. Considerando as variações entre os valores de referência citados, torna-se necessário a determinação de um intervalo de referência individualizado para cada método desenvolvido.

Uma vez que a quantificação de MDA é amplamente utilizada como um marcador do dano oxidativo em moléculas lipídicas, é importante o desenvolvimento de novas metodologias que forneçam resultados com adequada sensibilidade e especificidade. Também, as condições pré-analíticas e analíticas devem ser otimizadas e validadas, incluindo a determinação da estabilidade de reagentes, analito e produto da reação de derivatização. O presente estudo consiste no desenvolvimento e validação de uma metodologia para quantificação de MDA plasmático por CLAE com detector de arranjo de diodos, utilizando o DNPH como derivatizante. Com o propósito de aumentar a seletividade da determinação desenvolvida, foi utilizado um detector espectrofotométrico com arranjo de diodos (DAD), permitindo a obtenção de espectros de varredura do analito, a comparação com espectros de referência e a avaliação da pureza espectral dos picos.

\section{MATERIAL E MÉTODOS}

\section{Reagentes}

Os reagentes 1,1,3,3-tetraetoxipropano e 2,4dinitrofenilhidrazina foram adquiridos da Sigma Chemical Company (St. Louis, EUA). Acetonitrila grau HPLC foi fornecida pela Merck (Darmstadt, Alemanha). Ácido acético, ácido clorídrico, ácido sulfúrico e ácido perclórico foram adquiridos da Casa da Química (Diadema, Brasil). Água foi obtida por destilação e deionização e purificada adicionalmente com um sistema Elga Purelab Ultra SC da Elga Labwater (Lane End, Reino Unido).

A solução estoque de MDA (10 mM) foi preparada como descrito em Sim et al. (2003) a partir de 1,1,3,3tetraetoxipropano e $\mathrm{H}_{2} \mathrm{SO}_{4} 1 \%(\mathrm{v} / \mathrm{v})$. A solução derivatizante foi preparada pela adição de $25,5 \mathrm{mg}$ de $2,4-$ 
dinitrofenilhidrazina em $\mathrm{HCl} 2 \mathrm{M}$, no volume final de $25 \mathrm{~mL}$ e foi armazenada em alíquotas de $2 \mathrm{~mL}$ a $-20{ }^{\circ} \mathrm{C}$. As soluções de trabalho de MDA, nas concentrações de 10 e 100 $\mu \mathrm{M}$, foram preparadas através de sucessivas diluições da solução-mãe com água purificada. A fase móvel foi preparada através da adição de $620 \mathrm{~mL}$ de água ultra-purificada, acidificada com ácido acético $0,2 \%(\mathrm{p} / \mathrm{v}) \mathrm{pH} 3,0$, filtrados com membrana de acetato de celulose $0,45 \mu \mathrm{m}$ (Schleicher e Schuell, Alemanha), a $380 \mathrm{~mL}$ de acetonitrila. A fase móvel foi desgaseificada por sonicação em banho ultrasônico antes da sua utilização.

\section{Análise cromatográfica}

O sistema cromatográfico era composto por um sistema quaternário de bombas LC-10AT, módulo controlador SCL-10A, desgaseificador DGV-14A, forno de coluna CTO-10AS, auto-injetor SIL-10AF e detector de arranjo de diodos (DAD) SPD-M10A. O sistema foi controlado pelo programa Class VP 6.13 SP2 (Shimadzu, Kyoto, Japão). A separação foi realizada em uma coluna Shim-Pack RP$18 \mathrm{e}(150 \times 4,6 \mathrm{~mm}$, d.i. $5 \mu \mathrm{m})$, a qual foi protegida por uma pré-coluna Shim-Pack G-ODS (10 x 4.0 mm, d.i. $5 \mu \mathrm{m})$, ambas da Shimadzu (Kyoto, Japão). Os cromatogramas foram monitorados em $310 \mathrm{~nm}$, com aquisição de espectros de varredura entre 200 e $380 \mathrm{~nm}$. Foram injetados $50 \mu \mathrm{L}$ da amostra, com eluição isocrática com fluxo de $1 \mathrm{~mL} / \mathrm{min}$. A coluna foi mantida a $30{ }^{\circ} \mathrm{C}$ durante a análise.

\section{Preparação da amostra}

Inicialmente, a amostra $(100 \mu \mathrm{L}$ de plasma $)$ foi hidrolisada através da adição de $200 \mu \mathrm{L}$ de $\mathrm{NaOH}$ 1,5 M para obtenção do MDA livre das proteínas plasmáticas. Esta mistura foi incubada a $60{ }^{\circ} \mathrm{C}$ por 30 minutos, condições previamente determinadas para hidrólise alcalina (Pilz, Meineke, Gleiter, 2000). Após, foram adicionados à amostra $200 \mu \mathrm{L} \mathrm{de}$ $\mathrm{H}_{2} \mathrm{ClO}_{4} 10 \%(\mathrm{v} / \mathrm{v})$, seguido de homogeneização em agitador tipo vórtex por 1 minuto. A mistura foi centrifugada por 10 minutos em microcentrífuga refrigerada a $4^{\circ} \mathrm{C}$, com velocidade de $14.500 \mathrm{~g}$. Então, $250 \mu \mathrm{L}$ do sobrenadante foram transferidos para tubo de polipropileno de $2 \mathrm{~mL}$, onde foram adicionados de $25 \mu \mathrm{L}$ da solução derivatizante de DNPH. A reação ocorreu em temperatura ambiente, ao abrigo da luz, durante $30 \mathrm{~min}$. Uma alíquota de $50 \mu \mathrm{L}$ da solução resultante foi injetada no sistema CLAE-DAD.

\section{Curva de calibração}

Para preparação dos calibradores, foi utilizado pool de amostras de plasma no qual a área relativa ao pico de
MDA-DNPH foi determinada em sextuplicata. A curva de calibração foi obtida através da adição-padrão das soluções trabalho de MDA em amostras de plasma, a fim de obter as concentrações adicionadas de 1,$5 ; 3 ; 5 ; 10 ; 20$ e $38 \mu \mathrm{M}$. A área média relativa ao pico de MDA-DNPH do pool foi subtraída das áreas obtidas com os valores adicionados de MDA. Todas as concentrações foram analisadas em sextuplicata e a média das determinações foi utilizada para a construção da curva de calibração.

A curva de calibração foi construída através da determinação da correlação entre área obtida para o pico cromatográfico do produto MDA-DNPH (y) e concentrações de MDA adicionadas ao plasma (x). A curva de calibração foi avaliada através do seu coeficiente de determinação $\left(\mathrm{r}^{2}\right)$ e análise de variância (ANOVA).

\section{Parâmetros de validação}

O limite de detecção e de quantificação foram determinados segundo Shah et al. (2000), calculados como 3,3 e 10 vezes a área do ruído da linha de base provenientes da matriz, respectivamente.

A precisão e a exatidão do método foram determinadas adicionando quantidades conhecidas de MDA a amostras de plasma, conforme descrito no ítem curva de calibração, obtendo concentrações finais adicionadas de MDA de 1,$5 ; 3 ; 8 ; 15$ e $30 \mu \mathrm{M}$. Os testes foram realizados em triplicata, em 3 dias diferentes. As 9 concentrações obtidas para cada nível de concentração foram submetidas à análise de variância (ANOVA), considerando dia como variável agrupadora, a fim de determinar a precisão intraensaios e inter-ensaios. A precisão foi expressa como coeficiente de variação percentual (C.V.\%). A exatidão foi calculada utilizando os mesmos dados, comparando a média das concentrações obtidas em cada nível de concentração com a concentração nominal e foi expressa como porcentagem da concentração adicionada.

A especificidade do método foi determinada através da análise de 6 amostras de plasma de indivíduos diferentes, avaliando a presença de potenciais interferentes na análise cromatográfica, segundo Shah et al. (2000). Adicionalmente, todos os picos relativos ao MDA obtidos no estudo de validação foram avaliados com respeito à similaridade espectral com amostra de referência e à sua pureza espectral.

A estabilidade no processo foi avaliada através da análise de amostras de plasma contendo MDA nas concentrações de 18 e $38 \mu \mathrm{M}$ mantidas em temperatura ambiente e protegidas da luz, em intervalos de 2 horas, durante 10 horas. Este experimento foi realizado em dois dias consecutivos. 


\section{Estudos de estabilidade}

A estabilidade da solução de trabalho de MDA na concentração de $10 \mu \mathrm{M}$ foi avaliada nas temperaturas de -20 e $4{ }^{\circ} \mathrm{C}$. Alíquotas desta solução foram analisadas nos dias 1 , $2,6,8,15,16,17,21,23,28$ e 29. A concentração de MDA nas alíquotas foi determinada através de espectrofotometria na região do ultravioleta, com medidas de absorbância em 245 nm, segundo Korchazhkina, Exley e Spencer (2003).

A estabilidade da solução derivatizante de DNPH, mantida a $-20{ }^{\circ} \mathrm{C}$ e separada em alíquotas, foi avaliada em 11 diferentes dias ao longo de um período de 36 dias (dias $1,2,6,7,8,13,14,20,27,35$ e 36). A estabilidade foi avaliada através da medida da absorbância da solução derivatizante nos comprimentos de onda 265, 361 e 628, que são máximos de absorção do DNPH.

A estabilidade do MDA em amostras de plasma foi determinada a partir da análise de amostras contendo 13 $\mu \mathrm{M}$ de MDA, armazenadas a $-20^{\circ} \mathrm{C}$, durante um período de 35 dias (dias 1, 6, 9, 13, 22, 28 e 35). Foram consideradas estáveis amostras cujas concentrações de MDA apresentaram variações inferiores a $10 \%$, com respeito à concentração inicial, durante o período de armazenamento.

\section{Valores de referência}

O presente estudo foi aprovado pelo Comitê de Ética em Pesquisa do Centro Universitário Feevale (Parecer $\mathrm{n}^{\circ}$ 2.08.03.06.443). A amostra foi composta por um total de 46 indivíduos. Os indivíduos foram convidados a participar como voluntários e responder a um questionário sobre qualidade de vida. Após a avaliação dos questionários, 38 indivíduos foram selecionados levando em conta os seguintes critérios de inclusão: idade entre 20 e 40 anos, sem relato de doenças crônicas, não fumantes, não praticantes de exercício físico intenso e não usuários de medicamentos, incluindo suplementos vitamínicos (exceto contraceptivos orais), os quais podem influenciar os níveis plasmáticos de MDA (Kanter, Nolte, Holloszy, 1993). Os demais voluntários ( $\mathrm{n}=8)$ que não atendiam a estas características foram excluídos do estudo. Foram coletados $4 \mathrm{~mL}$ de sangue periférico em tubos contendo EDTA, que foram imediatamente centrifugados para separação do plasma e armazenado a $-20^{\circ} \mathrm{C}$ até a sua análise. Os valores foram expressos através da média \pm desvio padrão das concentrações de MDA determinados no grupo em estudo.

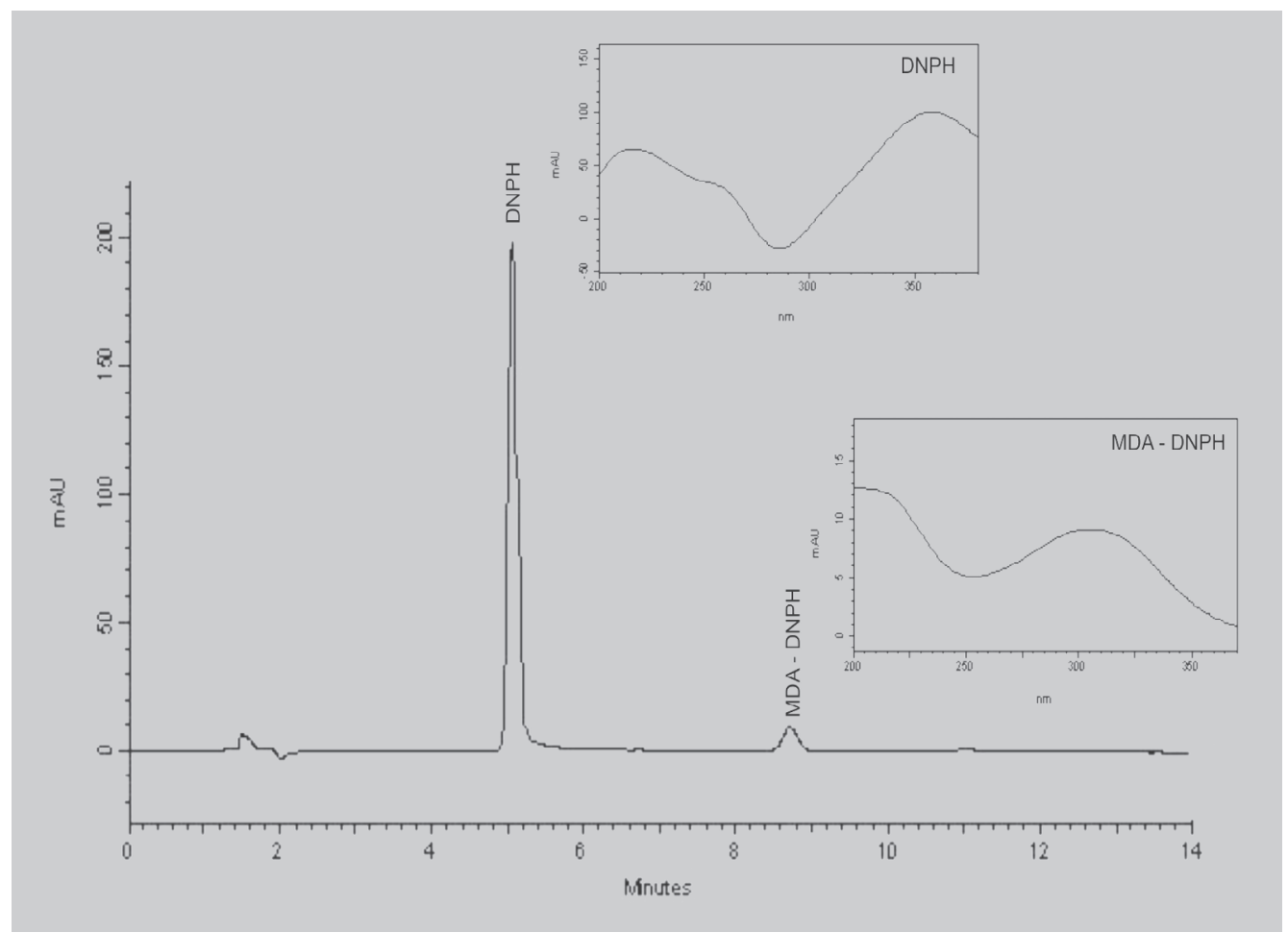

FIGURA 1 - Cromatograma $(310 \mathrm{~nm})$ de solução MDA $4 \mu \mathrm{M}$, após derivatização com DNPH. Tempo de retenção do DNPH: 5,2 minutos. Tempo de retenção do produto MDA-DNPH: 8,8 minutos. Os espectros de absorção obtidos pelo DAD com varredura entre 200 e 380 nm também estão apresentados. 


\section{RESULTADOS E DISCUSSÃO}

\section{Separação e detecção cromatográfica}

Foi possível a separação do analito, sem a presença de picos interferentes endógenos no cromatograma. $\mathrm{O}$ tempo de retenção médio do produto MDA-DNPH foi de 8,8 min, e o tempo total da análise cromatográfica foi de $14 \mathrm{~min}$ (Figura 1). O pico cromatográfico referente ao DNPH, presente em excesso na amostra, apresentou tempo de eluição médio de 5,2 min.

A identificação do produto MDA-DNPH foi realizada através do tempo de retenção e também através da comparação do seu espectro de absorção UV, na faixa de comprimentos de onda entre 200 e $380 \mathrm{~nm}$ (Figura 1), com espectros obtidos com amostras de referência. Através do detector DAD foi possível avaliar a pureza espectral dos picos cromatográficos obtidos, aumentando a especificidade da determinação (Pragst, Herzler, Erxleben, 2004).

\section{Curva de calibração e validação}

A curva de calibração em plasma adicionado com 1,$5 ; 3 ; 5 ; 10 ; 20$ e $38 \mu \mathrm{M}$ de MDA apresentou linearidade adequada $\left(\mathrm{r}^{2}=0,9982\right)$, com inclinação 4170,1 e intercepto 191,33. Alternativamente, foi realizada a calibração utilizando calibradores com MDA em amostras aquosas. A curva obtida empregando matriz aquosa apresentou equação de regressão linear y $=$ $3954,5 \mathrm{x}+2183,9$ e r $^{2} 0,9888$. Ambas as curvas apresentaram significativo paralelismo, representado por um $\mathrm{r}^{2}$ de 0,9947 . Entretanto, o uso de curvas de calibração obtida em calibradores preparados em matriz aquosa, como relatado nos trabalhos de Steghens et al. (2001), Pilz, Meineke e Gleiter (2000), Karatas, Karatepe e Baysar (2002), Mao et al. (2006) e Mateos et al. (2005) leva a uma subestimação dos valores de MDA plasmático, consideração que a recuperação absoluta do procedimento de preparo da amostra encontra-se na faixa de 75 a $81 \%$. Desta forma, o método com calibração baseada em amostras preparadas em plasma foi selecionado para o estudo de validação e o posterior emprego na determinação de valores de referência.

O teste $\mathrm{F}$ para não significância heterocedástica (á $=0,01)$ revelou que a curva de calibração plasmática tem perfil homocedástico, indicando que as variâncias do termo de erro do modelo são constantes para todas as observações (Cribari-Neto, Soares, 2003). Foi desnecessário, portanto, o ajuste da curva para a forma de regressão linear ponderada. A regressão apresentou falta-deajuste não significativa, para um nível de confiança de $5 \%$.

Os parâmetros recuperação, precisão intra-dias, precisão inter-dias e exatidão, avaliados nas concentrações 1,$5 ; 3 ; 5 ; 8 ; 15$ e $30 \mu \mathrm{M}(\mathrm{n}=3)$ em três diferentes dias, foram calculados através de ANOVA e estão de acordo com os valores determinados para validação de métodos (Shah et al., 2000), conforme expresso na Tabela I. Nas análises de 6 amostras de plasma diferentes não foram observados interferentes no tempo de retenção do produto MDADNPH. Os picos de MDA-DNPH apresentaram pureza espectral em todas as análises.

Os limites de detecção e quantificação, determinados com base na relação sinal:ruído, conforme Shah et al. (2000), foram de 0,11 e $0,38 \mu \mathrm{M}$, respectivamente.

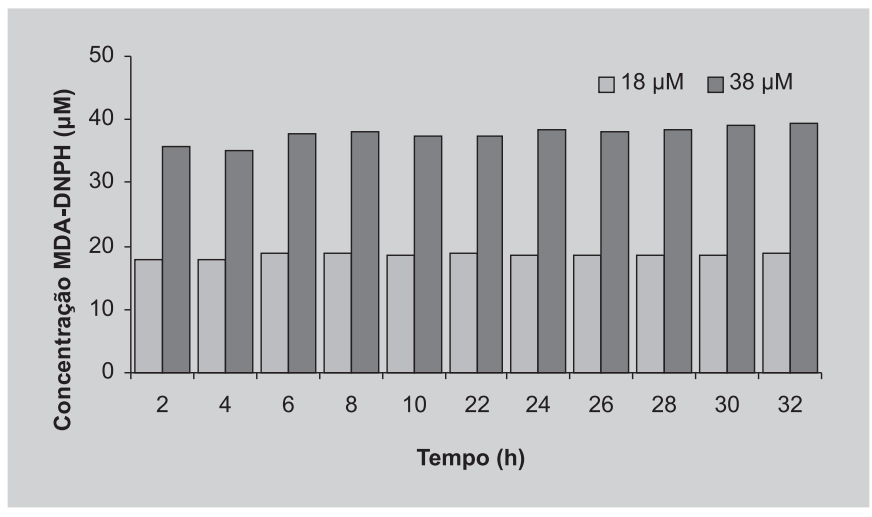

FIGURA 2 - Estabilidade no processo, plasma 18 e $38 \mu \mathrm{M}$ MDA após 2, 4, 6, 8, 10, 22, 24, 26, 28, 30 e 32 horas da etapa de derivatização.

TABELA I - Recuperação, precisão e exatidão para a determinação de MDA em plasma (n = 3)

\begin{tabular}{lcccc}
\hline Concentração $(\mu \mathrm{M})$ & Recuperação (\%) & Precisão intra-dias $(\mathrm{CV} \%)$ & Precisão inter-dias $(\mathrm{CV} \%)$ & Exatidão (\%) \\
\hline 1,5 & 75,5 & 5,16 & 2,42 & 105,55 \\
3 & 74,2 & 8,02 & 6,29 & 104,06 \\
8 & 76,3 & 14,69 & 7,13 & 99,37 \\
15 & 79,4 & 7,68 & 6,93 & 98,21 \\
30 & 81,4 & 3,67 & 4,63 & 101,57 \\
\hline
\end{tabular}




\section{Estabilidade}

Através da avaliação da estabilidade no processo durante dois dias, nas concentrações 18 e $38 \mu \mathrm{M}$, armazenadas em temperatura ambiente e protegidas da luz, observou-se que o produto derivatizado não apresenta, nestas condições, importantes variações na sua concentração (Figura 2). Isto indica que após o preparo das amostras existe um tempo razoável, de pelo menos 30 horas, para a análise cromatográfica, o que permite a utilização do procedimento em condições de rotina laboratorial. Este achado está de acordo com o verificado por Pilz, Meineke e Gleiter (2000), na avaliação da estabilidade do derivatizado por período de 20 horas sob as mesmas condições de armazenamento.

A solução padrão de MDA $(10 \mu \mathrm{M})$ armazenada a -20 e $4{ }^{\circ} \mathrm{C}$, manteve-se estável em ambas as temperaturas durante o período de 35 dias em que foi analisada. A solução derivatizante permaneceu estável durante 35 dias sob armazenamento a $-20^{\circ} \mathrm{C}$, ao contrário do que é citado na literatura(Mao et al., 2006). Estas soluções podem, portanto, ser preparadas mensalmente e estocadas sob refrigeração, diminuindo a produção de resíduos laboratoriais e o gasto com estes reagentes.

Diferentemente de estudos anteriores (Pilz, Meineke, Gleiter, 2000, Sim et al., 2003; Nielsen et al., 1997; Suttnar, Masova, Dyr, 2001; Mateos et al., 2005), nos quais as amostras de plasma para quantificação de MDA são armazenadas a $-80^{\circ} \mathrm{C}$ até o momento da análise, neste trabalho demonstramos que os níveis plasmáticos de MDA mantêm-se estáveis por 35 dias, quando as amostras são armazenadas a $-20^{\circ} \mathrm{C}$ (Figura 3 ). Desta forma, mesmo laboratórios que possuem apenas congeladores convencionais podem armazenar amostras de plasma por um período de tempo aceitável.

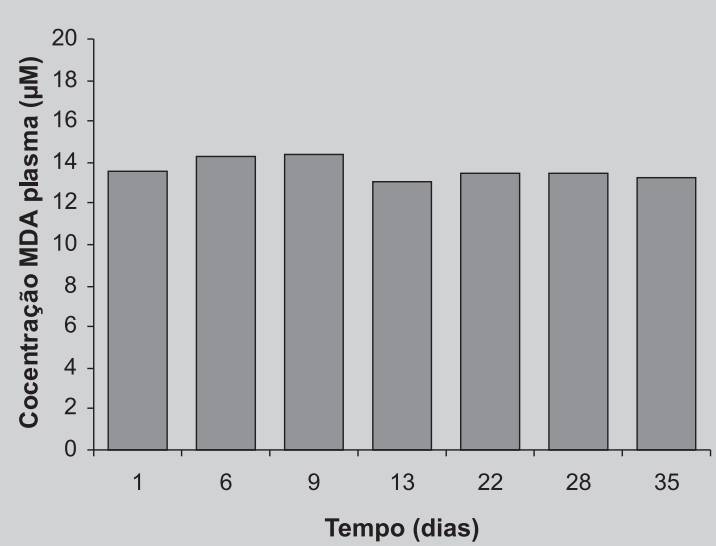

FIGURA 3 - Estabilidade do MDA plasmático armazenado a $-20{ }^{\circ} \mathrm{C}$, por 35 dias.

\section{Derivatização}

Na derivatização do MDA com TBA (Londero, Greco,1996; Grotto et al., 2007), as condições experimentais propiciam a geração in vitro de produtos de lipoperoxidação, contribuindo para uma menor especificidade do método. O uso de DNPH como derivatizante apresenta como vantagem, além da melhoria das características de absortividade no UV, o uso de condições reacionais mais brandas, em temperatura ambiente. O produto MDA-DNPH, nas condições de derivatização utilizadas, atinge concentrações máximas entre 15 e 30 minutos. O uso de outros derivatizantes como o diaminonaftaleno (DAN) e a FMOC-hidrazina já foram propostos nos trabalhos de Steghens et al. (2001) e Mao et al. (2006) respectivamente, porém estes derivatizantes requerem tempo de incubação mais longos às reações (180 minutos para o DAN e 4 horas para a FMOC-hidrazina).

\section{Valores de referência}

Os valores de referência foram obtidos a partir da análise dos níveis plasmáticos de MDA em um grupo de 46 indivíduos voluntários do estudo. A amostra foi composta por 38 voluntários que atenderam os critérios de inclusão (27 mulheres e 11 homens). Foram excluídos do estudo 2 indivíduos que apresentavam doença crônica, 4 fumantes e 2 usuários de medicamentos. $\mathrm{O}$ valor médio do nível de MDA na amostra foi de 3,31 $\mu \mathrm{M}+0,38(\mathrm{n}=38)$, considerando-se os valores de $3,24 \pm 0,34(\mathrm{n}=27)$ para mulheres e $3,47 \pm 0,44$ para homens $(n=11)$.

\section{Comparação com outros estudos}

Na Tabela II são apresentados parâmetros de validação e valores de referência dos estudos de Pilz, Meineke e Gleiter (2000), Sim et al. (2003) e Mateos et al. (2005), os quais utilizam condições experimentais semelhantes às empregadas no presente trabalho, ou seja, hidrólise alcalina, precipitação protéica ácida e derivatização com DNPH. Pilz, Meineke e Gleiter (2000) encontraram valores médios de 2,16 $\pm 0,29(\mathrm{n}=12)$, enquanto Sim et al. (2003) obtiveram valores de referência em indivíduos saudáveis na ordem de 13,8 $\pm 1,32(\mathrm{n}=20)$. A grande variabilidade dos valores encontradas nos diferentes métodos pode ser explicada devido a diferenças no processo de hidrólise, já que grande parte do MDA encontra-se ligado a proteínas plasmáticas. Os valores encontrados por Sim et al. (2003), bem mais altos do que os determinados por Pilz, Meineke e Gleiter (2000) e do que os níveis obtidos no presente trabalho, são justificados pelos autores como resultados de um processo de hidrólise mais 
TABELA II - Métodos para detecção de MDA por CLAE com uso de DNPH como derivatizante.

\begin{tabular}{lcccccc}
\hline Detector & $\begin{array}{c}\text { Volume } \\
\text { amostra }(\mu \mathrm{L})\end{array}$ & $\begin{array}{c}\text { Matriz curva } \\
\text { calibração }\end{array}$ & $\begin{array}{c}\text { Recuperação } \\
\text { absoluta }(\%)\end{array}$ & LOD $(\mu \mathrm{M})$ & $\begin{array}{c}\text { Valores de referência } \\
\text { de MDA }(\mu \mathrm{M})\end{array}$ & Referência \\
\hline DAD & 250 & $1 \% \mathrm{H}_{2} \mathrm{SO}_{4}$ & 93,6 & 0,30 & $2,16 \pm 0,29$ & Pilz, Meineke, Gleiter $(2000)$ \\
UV-VIS & 50 & plasma & 88,5 & 2,10 & $13,8 \pm 1,32$ & Sim et al. $(2003)$ \\
UV-VIS & 250 & tampão PBS & $96,3-99,8$ & 0,10 & n.d. & Mateos et al. $(2005)$ \\
DAD & 100 & plasma & $75,5-81$ & 0,11 & $3.31 \pm 0.38 \mu \mathrm{M}$ & p.t. \\
\hline
\end{tabular}

DAD: detector de arranjo de diodos; UV-VIS: ultra-violeta-visível; n.d.: não disponível; p.t.: presente trabalho.

efetivo. Entretanto, ao replicarmos as condições de hidrólise de Sim et al. (2003), não obtivemos valores significativamente diferentes.

Desta forma, o presente estudo, em comparação com aqueles constantes na Tabela II, é o único a conjugar a utilização de pequenos volumes de amostra com elevada sensibilidade, bem como a avaliar a estabilidade do analito e do produto de derivatização, tanto em condições de armazenamento como em processo. Também se deve destacar que diferentemente dos estudos de Pilz, Meineke e Gleiter (2000) e de Mateos et al. (2005), as amostras empregadas no presente estudo de validação foram preparadas em plasma humano, conforme recomendado por Shah et al. (2000), e por tanto levam em consideração a presença de interferentes endógenos e a recuperação absoluta do método.

Cabe destacar a ampla variabilidade de valores de referência relatados na literatura. As diferenças nos índices basais de MDA podem também ser justificadas pelas diferenças étnicas e culturais das populações estudadas, incluindo hábitos alimentares dos indivíduos. Entretanto, a realização de estudos interlaboratoriais com as mesmas amostras pode ser uma forma de identificar possíveis erros sistemáticos nas diferentes técnicas utilizadas e conseqüentemente obter um maior consenso quanto aos níveis basais do MDA em indivíduos adultos saudáveis.

\section{CONCLUSÕES}

Foi desenvolvido um método para determinação de MDA por CLAE-DAD, após derivatização com DNPH, utilizando coluna de fase reversa e eluição isocrática. As condições experimentais foram otimizadas demonstrando que existe estabilidade tanto do reagente de derivatização e quanto do analito, permitindo sua utilização em condições laboratoriais usuais. Nestas condições experimentais, o método apresentou precisão de $2,4-14,7 \%$ e exatidão de 98,2 - 105,5 \%. O limite de quantificação foi de $0,38 \mu \mathrm{M}$. O método proposto é sensível, preciso e exato. Ainda, utiliza condições experimentais que não propici- am a geração de MDA durante o ensaio. É um método altamente específico, devido ao uso de detector de arranjo de diodos, que possibilita a determinação da pureza dos picos cromatográficos. Além disso, a reação de derivatização forma um produto facilmente separado por CLAE, sem interferentes. Devido à linearidade obtida com a adição de padrões, torna-se dispensável o uso de padrão interno. Além disso, foi estabelecido o intervalo de referência das concentrações médias de MDA para o método, a partir das análises de amostras de indivíduos adultos saudáveis, de $3,31 \mu \mathrm{M} \pm 0,38(\mathrm{n}=38)$, dentre este grupo considera-se os valores para mulheres de 3,24 \pm $0,34(\mathrm{n}=27)$ e $3,47 \pm 0,44$ para homens $(\mathrm{n}=11)$.

\section{ABSTRACT}

\section{Preanalytical and validation studies for the determi- nation of malondialdehyde in human plasma through high performance liquid chromatography after derivatization with 2,4-dinitrophenylhydrazine}

Malondialdehyde (MDA) is an important biomarker for the evaluation of oxidative stress status. The aim of this study was to develop a method for plasma MDA quantification by high performance liquid chromatography with diode-array detection (HPLC-DAD), following derivatization with 2,4dinitrophenylhydrazine (DNPH), evaluating the main preanalytical variables. The calibration curve in plasma $(0$ to $40 \mu M)$ presented high linearity $\left(r^{2}=0.998\right)$. Main validation parameters were: recovery: $78 \%$; LOD: $0.11 \mu \mathrm{M}$ and LOQ: $0.38 \mu \mathrm{M}$. The MDA values obtained in healthy volunteers $(n=38)$ were $3.31 \pm 0.38 \mu M($ mean $\pm S D)$. Stability studies of MDA standard solution and derivatizing reagent and plasma MDA indicated that the standard solution can be stored at -20 and $4{ }^{\circ} \mathrm{C}$, remaining stable for at least 30 days.

UNITERMS: Oxidative stress. Malondialdehyde. High performance liquid chromatography. 2,4-dinitrophenylhydrazine. 


\section{AGRADECIMENTOS}

Ao Centro Universitário Feevale, pelo apoio financeiro.

\section{REFERÊNCIAS BIBLIOGRÁFICAS}

ANDRADE J.R., D.R., SOUZA, R.B., SANTOS, S.A., ANDRADE, D.R. Os radicais livres de oxigênio e as doenças pulmonares J. Bras. Pneumol., v.31, n. 1, p.6068, 2005.

BAGIS, S.; TAMER, L.; BILGIN, G.S.R.; GULER, H.; ERDOGAN, B.E.C. Free radicals and antioxidants in primary fibromyalgia: an oxidative stress disorder? Rheumatol. Int., v.25, n.3, p.188-190, 2005.

CRIBARI-NETO, F.; SOARES, A.C.N. Inferência em modelos heterocedásticos. Rev. Bras. Econ., v.57, n.2, p.319-335, 2003.

DEL RIO, D.; STEWART, A.J.; PELLEGRINI, N. A review of recent studies on malondialdehyde as toxic molecule and biological marker of oxidative stress. Nutr. Metab. Cardiovasc. Dis., v.15, p.316-328, 2005.

FERREIRA, A.L.A.; MATSUBARA, L.S. Radicais livres: conceitos, doenças relacionadas, sistema de defesa e estresse oxidativo. Rev. Assoc. Med. Bras., v.43, n.1, p.61-68, 1997.

GROTTO, D.; SANTA MARIA, L.D.; BOEIRA, S.; VALENTINI, J.; CHARÃO, M.F.; MORO, A.M.; NASCIMENTO, P.C.; POMBLUM, V.J.; GARCIA, S.C. Rapid quantification of malondialdehyde in plasma by high performance liquid chromatography - visible detection. J. Pharm. Biomed. Anal., v.43, p.619-624, 2007.

KANTER, M.M.; NOLTE L.A.; HOLLOSZY, J.O. Effects of an antioxidant vitamin mixture on lipid peroxidation at rest and postexercise. J. Appl. Physiol., v.74, p.965-969, 1993

KARATAS, F.; KARATEPE M.; BAYSARA. Determination of free malondialdehyde in human serum by highperformance liquid chromatography. Anal. Biochem., v.311, p.76-79, 2002.
KORCHAZHKINA, O.; EXLEY, C.; SPENCER, S.A. Measurement by reversed-phase high-performance liquid chromatography of malondialdehyde in normal human urine following derivatisation with 2,4dinitrophenylhydrazine. J. Chromatogr. B: Anal. Technol. Biomed. Life. Sci., v.794, n.2, p.353-362, 2003.

LONDERO D.; GRECO, P.L. Automated high-performance liquid chromatographic separation with spectrofluorometric detection of a malondialdehydethiobarbituric acid adduct in plasma. J. Chromatogr. A, v.729, p.207-210, 1996.

MAO, J.; ZHANG, H.; LUO, J.; LI, L.; ZHAO, R.; ZHANG, R.; LIU, G. New method for HPLC separation and fluorescence detection of malonaldehyde in normal human plasma. J. Chromatogr. B: Anal. Technol. Biomed. Life Sci., v.832, n.1, p.103-108, 2006.

MATEOS, R.; LECUMBERRI, E.; RAMOS, S.; GOYA, L.; BRAVO, L. Determination of malondialdehyde (MDA) by high-performance liquid chromatography in serum and liver as a biomarker for oxidative stress: Application to a rat model for hypercholesterolemia and evaluation of the effect of diets rich in phenolic antioxidants from fruits. $J$. Chromatogr. B: Anal. Technol. Biomed. Life Sci., v.827, n.1, p.76-82, 2005.

NIELSEN, F.; MIKKELSEN, B.B.; NIELSEN, J.B.; ANDERSEN, H.R.; GRANDJEAN, P. Plasma malondialdehyde as biomarker for oxidative stress: reference interval and effects of life-style factors. Clin. Chem., v.43, n.7, p.1209-1214, 1997.

ÖZGÜNER, M.F.; DELÝBAP N.; TAHAN V.; KOYU A.; KÖYLÜ H. Effects of industrial noise on the blood levels of superoxide dismutase, glutathione peroxidase and malondialdehyde. Eas. J. Med., v.4, n.1, p.13-15, 1999.

PILZ, J.; MEINEKE, I.; GLEITER, C. Measurement of free and bound malondialdehyde in plasma by highperformance liquid chromatography as the 2,4dinitrophenylhydrazine derivative. J. Chromatogr. B: Anal. Technol. Biomed. Life Sci., v.742, p.315-325, 2000.

PRAGST, F.; HERZLER, M.; ERXLEBEN, B.T. Systematic toxicological analysis by high-performance liquid chromatography with diode array detection (HPLCDAD). Clin. Chem. Lab. Med., v.42, n.11, p.1325-1340, 2004. 
SHAH, V.P.; MIDHA, K.K.; FINDLAY, J.W.A.; HILL, H.M.; HULSE J.D.; MCGILVERAY, I.J.; MCKAY, G.; MILLER, K.J.; PATNAIK, R.N.; POWELL, M.L.; TONELLI, A.; VISWANATHAN, C.T.; YACOBI A. Bioanalytical Method Validation - A revisit with a decade of progress. Pharm. Res., v.17, n.12, p.1551-1557, 2000.

SIM, A.S.; SALONIKAS, C.; NAIDOO, D.; WILCKEN, D.E.L. Improved method for plasma malondialdehyde measurement by high-performance liquid chromatography using methyl malondialdehyde as an internal standard. J. Chromatogr. B: Anal. Technol. Biomed. Life Sci., v.785, p.337-344, 2003.

STEGHENS, J.P.; KAPPEL, A.L.V.; DENIS, I.; COLLOMBEL, C. Diaminonaphtalene, a new highly specific reagent for HPLC-UV measurement of total and free malondialdehyde in human plasma or serum. Free Radical. Biol. Med., v.31, n.2, p.242-249, 2001.
SUTTNAR, J.; MASOVA, L.; DYR, J.A. Influence of citrate and EDTA anticoagulants on plasma malondialdehyde concentrations estimated by high-performance liquid chromatography. J. Chromatogr. B: Anal. Technol. Biomed. Life Sci, v.751, n.1, p.193-197, 2001.

YAGI, K. A simple fluorometric assay for lipoperoxide in blood plasma. Biochem. Med., n.15, p.212-216, 1976.

YEO, H.C.; HELBOCK, H.J.; CHYU, D.W.; AMES, B.N. Assay of Malondialdehyde in Biological Fluids by Gas Chromatography-Mass Spectrometry. Anal. Biochem., v.220, n.2, p.391-396, 1994.

Recebido para publicação em 09 de agosto de 2007 Aceito para publicação em 17 de dezembro de 2007 